Mikrochim. Acta 117, 195-206(1995)

\title{
Immobilization of Proteins on Gold Coated Porous Membranes Via an Activated Self-Assembled Monolayer of Thioctic Acid
}

\author{
Chuanming Duan and Mark E. Meyerhoff* \\ Department of Chemistry, University of Michigan, Ann Arbor, MI 48109, U.S.A.
}

\begin{abstract}
A new methodology for efficient protein (e.g., antibodies, enzymes, etc.) immobilization on microporous nylon membranes for use in a variety of bioanalytical systems is introduced. The method utilizes an activated selfassembled monolayer (SAM) of thioctic acid on gold coated forms of the membranes. Via a carbodiimide mediated reaction, the protein is anchored to the gold surface through an amide bond with the terminal carboxyl group of the adsorbed thioctic acid. The immobilization efficiency is high ( $\sim 95 \%$ for a monoclonal immunoglobulin $\mathrm{G}(\mathrm{IgG})$ and the surface bound protein appears to be stable enough to resist any displacement by other proteins in a matrix as complex as serum. Immunological activity of immobilized antibody is retained as demonstrated via use of such membrances in colorimetric ELISA for human chorionic gonadatropin (hCG). The high protein immobilization efficiency, the high tensile strength of microporous nylon membranes, and the excellent electrochemical characteristics of gold make this approach very attractive for preparing biomembranes that should be useful in affinity chromatography, electrochemical immunosensing systems, flow-through enzyme reactors, etc.
\end{abstract}

Key words: protein immobilization, self-assembled monolayers, thioctic acid, ELISA.

Immobilization of proteins on solid phases [1-4] is important in food manufacturing [5], the pharmaceutical industry [6], biochemistry $[7,8]$, as well as in modern bioanalytical chemistry [9-13]. In the latter area, immobilized antibodies are often used to devise highly selective immunoassays for diagnostic purposes, while immobilized enzymes have played a major role in modern biosensor technology, flow-through analysis systems, etc. Proteins can be immobilized either physically or chemically on a solid support. Physical immobilization involves the

* To whom correspondence should be addressed 
adsorption of proteins onto a solid surface, or the entrapment of proteins inside a water-insoluble polymer lattice or within a semipermeable microcapsule. Chemical immobilization involves the formation of at least one covalent bond between the protein and the functionalized insoluble matrix. By far, chemical immobilization is the more stable and more popular of these two approaches.

Various solid supports have been explored for the immobilization of proteins [3]. Among the factors which must be considered in choosing a solid phase are its surface charge and hydrophilicity, its physical and chemical stability, the ease of activation, the interaction of the support with the analyte or sample solution, the availability of the matrix, and the capacity of the matrix to bind a given protein. An ideal matrix should not impose a denaturing or destabilizing effect upon the immobilized protein.

Microporous nylon membranes have been one of the most widely used matrices for protein immobilization because of their high protein binding capacity, natural hydrophilicity, and good physical and chemical stability. The method used often for immobilization of proteins on nylon involves the hydrolysis of the polymer to expose free carboxyl and amine groups and subsequent chemical reaction via a variety of coupling reagents (e.g., glutaraldehyde, carbodiimide, etc.) $[3,14]$. However, this approach disturbs the polymer structure and results in a relatively low protein binding capacity. As will be shown herein, these disadvantages can be overcome by coating the nylon membrane with a thin layer of gold.

Gold surfaces can be easily modified by self-assembled monolayers (SAM) of thioalkyl derivatives. Hickman et al. [15] and Rubenstein et al. [16] have reported the applications of SAM gold electrodes for $\mathrm{pH}$ and metal ion sensing. Sun et al. [17] have shown that a SAM of 4-aminothiophenol can be used to electrostatically bind given target species at a controlled solution $\mathrm{pH}$. Miller et al. [18] and Chidsey et al. [19] have investigated the influence of the chain length of the assembled derivatives and the packing density of the monolayer on the electron transfer through the SAM. Li and Weaver [20] have exploited the spontaneous strong adsorption of thioctic acid on gold through its two sulfur atoms to attach pentaaminecobalt $(3+)$ to the surface of electrodes. Recently, Cheng and Brajter-Toth [21] have studied the SAM of thioctic acid on a gold electrode prepared by deposition of gold on a single-crystal silicon wafer. They found that the self-assembly of thiotic acid on a smooth gold electrode can form an organized monolayer with the terminal carboxylic acid group in contact with solution controlling the electrochemical response of the electrode. The resulting electrode is stable and the monolayer is selectively permeable to certain solution phase electroactive species, depending on their charge and the $\mathrm{pH}$ of the test solution.

This work carries the modification one step further by activating the carboxyl group of the immobilized thioctic acid with a carbodiimide. Carbodiimides catalyze the formation of amide bonds between carboxylic acids and amines by activating the carboxylate to form an $\mathrm{O}$-acylurea. This intermediate can either be attacked by the amine directly to form the amide or it can be attacked by a second carboxylate to give the anhydride which can then be attacked by the amine, giving the amide and regenerating one of the carboxylates.

In the protein immobilization method proposed here (see Fig. 1), microporous nylon membrane discs (pore size: $0.2 \mu \mathrm{m}$, diameter: $6 \mathrm{~mm}$ ) are coated with a layer 
of gold ( $600 \AA$ thick). Upon the addition of a thioctic acid solution, a spontaneous interaction between sulfur and gold causes the disulfide bond within the thioctic acid molecule to break, with the subsequent formation of two thiolate bonds to the gold surface thereby forming a SAM of thioctic acid. The carboxyl group from thioctic acid is then further activated by 1-ethyl-3-(3-dimethylaminopropyl) carbodiimide hydrochloride (EDC) to form the active $\mathrm{O}$-acylurea intermediate. The amine group from proteins can attack this intermediate and form an amide bond to obtain protein immobilization with up to $95 \%$ efficiency. This membrane configuration has already been applied successfully for the development of a non-separation sandwich type electrochemical enzyme immunoassay for detecting proteins in matrices as complex as whole blood [22]. However, the methodology is quite general and could be useful in affinity chromatography of proteins, biosensor development, and the preparation of flow-through immuno- and enzymebased reactors. In this paper, we provide more details regarding the efficiency of protein immobilization by this method and examine the stability of the immobilized protein with respect to surface displacement when the protein-gold coated membranes are exposed to samples (e.g., serum) containing high concentrations of other proteins.

\section{Experimental}

\section{Apparatus}

Gold coating of the nylon membranes was accomplished with a Denton Vaccum Desk-11 cold sputter-etch unit. Scanning electron microscopy of the resulting membranes was carried out on a Hitachi-570 instrument (under Grant BSR-83-14092 from NSF). Absorbance measurements of various solutions were performed on a Perkin-Elmer Lambda Array 3840 UV-Vis Spectrophotometer with a 7300 Professional Computer.

\section{Reagents}

Alkaline phosphatase and bovine serum albumin were purchased from Sigma (Saint Louis, MO). (D, L)-thioctic acid and Tween-20 were obtained from Aldrich (Milwaukee, WI). The Micro BCA Protein Assay Reagent Kit, 4-nitrophenyl phosphate, and 1-ethyl-3-(3-dimethylaminopropyl) carbodimide (EDC) were obtained from Pierce (Rockford, IL). Anti-hCG (human chorionic gonadotropin) and anti-PSA (prostate specific antigen) monoclonal antibodies and alkaline phosphatase labeled second anti-hCG antibody were gifts from Hybritech Inc. (La Jolla, CA). The microporous nylon membrane, Nylaflo, with pore size of $0.2 \mu \mathrm{m}$, was a product of Gelman Science (Ann Arbor, MI). All other chemicals were reagent grade.

\section{Preparation of Gold Coated Microporous Nylon Membrane Discs and the Immobilization of Proteins}

A piece of microporous nylon membrane (diameter: $47 \mathrm{~mm}$ ) was put under an appropriate mask punched with seven $6 \mathrm{~mm}$ diameter holes. The masked membrane was then placed in the Denton Vacuum Desk-11 cold sputter-etch unit and coated with gold for 200 seconds. Each nylon membrane yielded seven disc-shaped gold coated areas, each having an outer diameter of $6 \mathrm{~mm}$ and a thickness of $\sim 600 \AA$. The gold coated membranes were immersed in $2 \%(\mathrm{w} / \mathrm{v})$ thioctic acid in absolute ethanol and shaken for 24 hours, after which they were rinsed with ethanol twice and dried. 
The membranes were then immersed in 1\%(w/v) EDC in anhydrous acetonitrile for 5 hours to activate the free carboxyl groups of the thioctic acid by forming the O-acylurea intermediate. After rinsing the membranes twice with acetonitrile, a layer of $\mathrm{PVC}(33 \% \mathrm{PVC}$ and $67 \%$ bis (2-ethylhexyl) sebacate, all w/w), dissolved in THF $(1: 6 \mathrm{w} / \mathrm{v})$, was cast around the gold discs. The $6-\mathrm{mm}$ diameter disk-shaped gold coatings were left untouched. Solutions of proteins $(57 \mu \mathrm{g}$ anti-hCG antibody, or $60 \mu \mathrm{g}$ anti- PSA antibody, or $57.1 \mathrm{U}(\sim 57 \mu \mathrm{g})$ alkaline phosphatase) in $30 \mu \mathrm{l}$ of $0.1 \mathrm{M}$ borate buffer, $\mathrm{pH} 8.75$, were deposited on the exposed gold coated microporous membrane discs for immobilization (see Fig. 1 for summary of protein immobilization chemistry). For comparison purposes, bare gold membrane discs without any chemical treatment, and gold membrane dises with a self-assembled monolayer of thioctic acid but not activated with EDC were also prepared and treated with the same amounts of the various proteins. All three membrane variations (bare gold, gold with a self-assembled monolayer of thioctic acid, and gold treated with thioctic acid and activated with EDC) were then refrigerated for further reaction and storage. Complete immobilization of proteins on the activated membranes occurs within 24 hours.

\section{Determination of the Immobilization Efficiency}

Following protein immobilization, a $6 \mathrm{~mm}$ inner diameter circular punctuator was used to cut out each $6 \mathrm{~mm}$ diameter gold coated disc from the larger nylon membrane. The discs immobilized with anti-PSA and anti-hCG monoclonal antibodies were washed four times, each time with $1 \mathrm{ml}$ portions of PBS buffer containing $0.1 \%$ Tween 20 for 30 min with shaking. The washing solutions ( $4 \mathrm{ml}$ total) were collected and later assayed to determine free protein levels. Protein concentrations were determined using a commercially available protein assay kit (Micro BCA Protein Assay Reagent Kit). A $1 \mathrm{ml}$ aliquot of reference standard, PBS buffer (blank), or washing solution from each disc was pipetted in triplicate into seperate test tubes. Then, $1 \mathrm{ml}$ of working reagent was added to each tube. All tubes were incubated at $60^{\circ} \mathrm{C}$ for $60 \mathrm{~min}$, then cooled to room temperature. Absorbance values were measured at $562 \mathrm{~nm}$ vs. water. A standard curve was constructed from reference standards and the protein concentrations in wash solutions were determined from the standard curve.

For discs with immobilized alkaline phosphatase, the determination of immobilization efficiency was slightly different. The wash solutions were combined with enzyme substrate and the enzyme concentration determined by colorimetric measurement of the reaction product. The washing procedure was the same as previously described except that the disks were washed three times, each with $2 \mathrm{ml}$ portions of PBS buffer. Sixty $\mu \mathrm{l}$ aliquots of washing solution from each disc were added to $1.94 \mathrm{ml}$ of $20 \mathrm{mM}$ p-nitrophenyl phosphate in $1.0 \mathrm{M}$ carbonate buffer, $\mathrm{pH} 10.0$. The mixture was incubated at room temperature for $5 \mathrm{~min}$ and the enzymatic reaction was terminated by the addition of $2 \mathrm{ml}$ of $2 \mathrm{M} \mathrm{NaOH}$. Absorbance of the final solution was measured at $405 \mathrm{~nm}$ on the Perkin-Elmer UV-Vis spectrophotometer.

\section{Determination of the Stability of the SAM Linkage}

The resistance toward the displacement of immobilized alkaline phosphatase by proteins in sheep serum was measured to test the stability of the above protein immobilization procedure. For this study, $2 \mathrm{U}(\sim 2 \mu \mathrm{g})$ alkaline phosphatase in $30 \mu \mathrm{l}$ borate buffer was added to each chemically modified gold coated membrane disc (diameter: $6 \mathrm{~mm}$ ). Immobilized membranes were divided into two groups. Following the completion of the immobilization, one group was assayed immediately (group A), then washed with TBS buffer $(0.02 \mathrm{M}$ Tris, $0.15 \mathrm{M} \mathrm{NaCl}, \mathrm{pH} 7.4$, containing $1 \mathrm{mM}$ $\mathrm{MgCl}_{2}$ ), incubated in sheep serum for 48 hours (subgroup B1), and then assayed again. At the completion of the immobilization procedure, the second group was incubated with sheep serum for 48 hours (subgroup B2) and then assayed. Membranes in both groups were assayed by incubating the punched $6 \mathrm{~mm}$ membrane discs with $2 \mathrm{ml}$ of $20 \mathrm{mM}$ p-nitrophenyl phosphate for one min, and 
then the enzyme reaction was halted by the addition of $2 \mathrm{ml}$ of $2 \mathrm{M} \mathrm{NaOH}$. Absorbance of the final solution was measured at $405 \mathrm{~nm}$.

Use of Membranes in a Sandwich Type Enzyme Immunoassay (EIA) for $h C G$

To illustrate the usefulness of the immobilization method, a sandwich-type EIA was developed using the gold coated microporous nylon membranes immobilized with capture anti-hCG antibody. After antibody immobilization, the membranes were immersed in $0.1 \mathrm{M}$ borate buffer, $\mathrm{pH} 8.75$, containing $5 \%(\mathrm{v} / \mathrm{v})$ ethanolamine for $5 \mathrm{~min}$ to block any unreacted but still active O-acylurea intermediates. The membrane discs were then rinsed with water and each was transferred to a fresh test tube. Various doses of hCG in $2 \mathrm{ml}$ of $0.1 \mathrm{M}$ Tris buffered saline (TBS), pH 7.4, containing $2 \%$ $(\mathrm{w} / \mathrm{v}) \mathrm{BSA}$ were added to each tube and incubated with the immobilized membrane discs for $30 \mathrm{~min}$. Then the membranes were washed three times with TBS and incubated with $0.25 \mathrm{mAbs}$ (mAbs: milliabsorbance) alkaline phosphatase labeled second anti-hCG Ab in TBS containing $2 \%$ BSA for $30 \mathrm{~min}(0.25 \mathrm{mAbs}$ corresponds to $392 \mathrm{U} / 1$ enzyme alkaline phosphatase activity as determined colorimetrically using 4-nitrophenyl phosphate as substrate in $1.0 \mathrm{M}$ carbonate buffer, $\mathrm{pH} 10$ ). Next, the membranes were washed extensively with TBS containing $0.04 \%$ Tween 20 . Finally, $2 \mathrm{ml}$ of $20 \mathrm{mM}$ 4-nitrophenyl phosphate in the carbonate buffer containing $1 \mathrm{mM} \mathrm{MgCl}{ }_{2}$ was added to each tube and incubated for one hour before terminating the reaction by the addition of $2 \mathrm{ml}$ of $2 \mathrm{M}$ $\mathrm{NaOH}$ to each tube. Absorbance of the final solution was measured at $405 \mathrm{~nm}$.

\section{Results and Discussion}

\section{Determination of Antibody Immobilization Efficiency by BCA Assay}

Bicinchoninic acid (BCA), in the form of its water soluble sodium salt, is a sensitive, stable, and highly specific complexing reagent for $\mathrm{Cu}^{+}$. In an alkaline medium, proteins react with $\mathrm{Cu}^{2+}$ to generate $\mathrm{Cu}^{+}$. Two molecules of BCA react with one cuprous ion $\left(\mathrm{Cu}^{+}\right)$to form a water soluble complex which exhibits a strong absorbance at $562 \mathrm{~nm}$. The concentration of this complex in solution is therefore proportional to the amount of protein present. The same calibration curve is applicable to the entire IgG group of proteins in the BCA assay. Thus, for this study, anti-hCG antibody was used as the standard for the BCA assay to determine the amount of monoclonal antibodies immobilized on the SAM/gold coated microporous membranes using the immobilization scheme illustrated in Fig. 1.

Table 1 summarizes the results obtained for the immobilization efficiency of anti-hCG and anti-PSA antibodies on various gold coated microporous nylon membranes. The first group of membranes was left untreated, and the second group contained an inactivated SAM of thioctic acid. The third group contained the EDC activated thioctic acid SAM. As shown, the same trend is observed for the immobilization of both antibodies on the gold coated discs. The membranes activated with EDC clearly provide the highest immobilization yield. The coverage of the gold surface with a layer of inactivated thioctic acid appears to effectively block protein immobilization, probably by preventing passive adsorption of proteins onto the gold. This blockage is of special importance when the gold surface is to be used as a biosensor directly in a physiological matrix (e.g., whole blood) without being fouled by high concentration of various proteins [22]. Passive adsorption of IgG molecules onto bare, untreated gold surfaces probably 


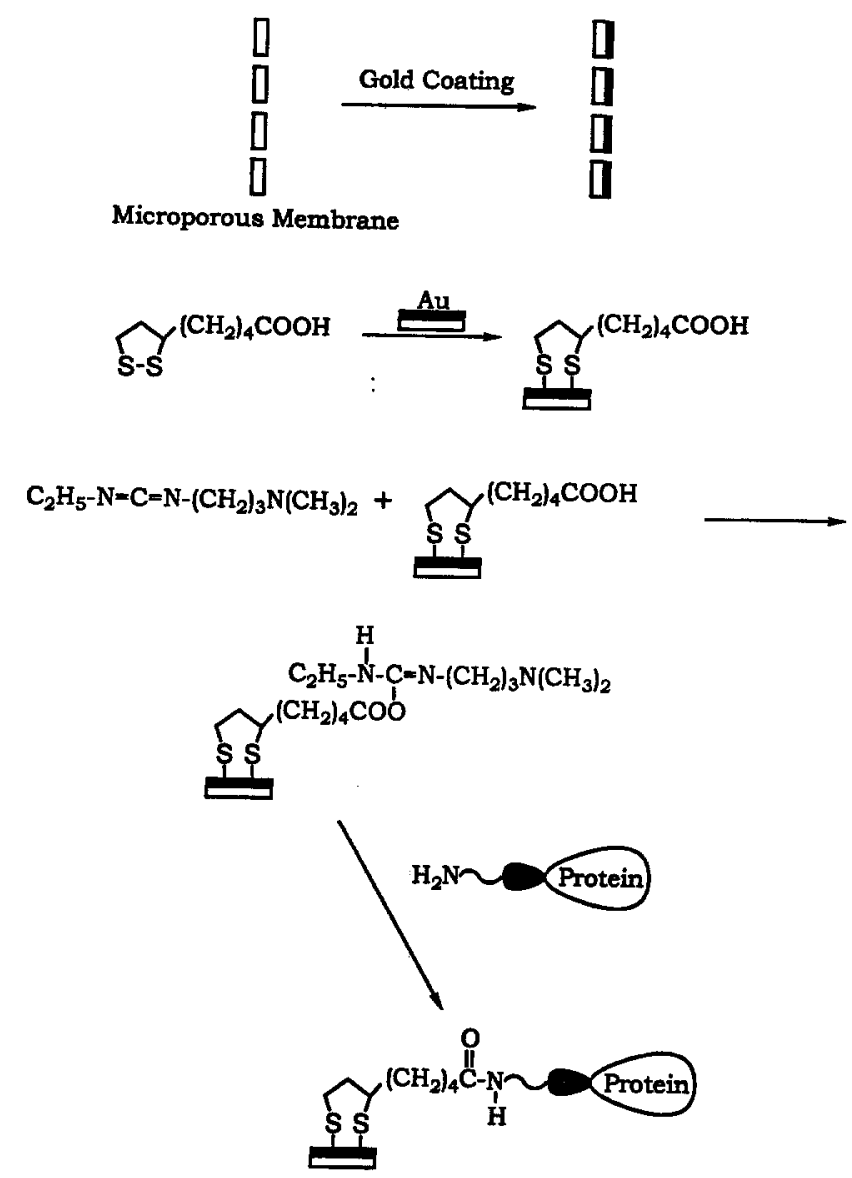

Fig. 1. Chemistry used for immobilization of proteins on gold coated microporous membranes

Table 1. Results for immobilization of monoclonal antibodies on disc-shaped gold coated microporous nylon membrane with diameter of $6 \mathrm{~mm}$

\begin{tabular}{llllccc}
\hline Type of membrane & Bare gold $^{\mathrm{a}}$ & \multicolumn{3}{l}{ SAM only } & \multicolumn{2}{c}{ SAM + EDC } \\
\hline Type of antibody & anti-hCG & anti-PSA & anti-hCG & anti-PSA & anti-hCG & anti-PSA \\
Immobilized Ab $^{\mathrm{d}}(\mu \mathrm{g})$ & $21.6 \pm 1.7$ & $23.0 \pm 0.8$ & $2.4 \pm 2.6$ & $3.2 \pm 2.1$ & $54.3 \pm 2.5$ & $56.8+2.0$ \\
Loading $^{\mathrm{e}}\left(\mu \mathrm{g} / \mathrm{cm}^{2}\right)$ & 76.4 & 81.4 & 8.5 & 11.3 & 192.1 & 201.0 \\
\% of immobilization & 37.9 & 38.3 & 4.2 & 5.3 & 95.3 & 94.7 \\
\hline
\end{tabular}

a Bare gold: antibodies applied directly to gold coated microporous nylon membrane without any chemical modification.

b SAM only: antibodies applied to gold coated membranes which is covered by a self-assembled monolayer of thioctic acid.

' SAM + EDC: antibodies applied to gold coated microporous nylon membrane treated first by thioctic acid, then further activated by EDC.

${ }^{d}$ Amount of antibody (mean \pm SD) obtained by subtracting antibody in the washing solution from the total antibody applied to each membrane disc.

- Amount of immobilized $\mathrm{Ab}$ on a geometric area of one $\mathrm{cm}^{2}$.

f Percentage of the amount of immobilized antibody over the total amount of antibody applied to each membrane disc. Each value represents the average of three measurements. 
occurs through endogeneous cysteine residues of the protein. Even though the efficiency of this spontaneous adsorption can reach as high as $38 \%$, passively adsorbed IgG molecules (anti-hCG Ab) exhibit no immunological reactivity when the resulting membrane is used in a solid phase ELISA for hCG (data not shown). Obviously, passive adsorption onto gold either denatures the IgG molecule or blocks its immunological reactive site. The inability of protein to adsorb on non-EDC activated thioactic acid treated gold membranes is significant because it means that such surfaces will exhibit relatively little non-specific adsorption in bioanalytical applications. When the described immobilization procedure is carried out (i.e., EDC activation), however, not only is the immobilization efficiency very high $(95 \%)$, but the immobilized antibody molecule also retains its immunological reactivity (see reference [22] and below).

Another useful feature of this membrane configuration is its high surface area. After being coated with a layer of gold, the membrane is still microporous. This is clearly illustrated by a scanning electron micrograph of the gold coated membrane (Fig. 2). Thus, due to surface roughness of the gold coating, very high protein loading is possible. Indeed, in the case of anti-hCG immobilization, the resulting discs possessed $192 \mu \mathrm{g} / \mathrm{cm}^{2}$ of antibody (area is geometric, not true gold surface area). The high surface area and protein loading achieved on the gold coated microporous nylon membrane makes it an ideal matrix for ELISA and other solid phase biochemical measurements.

The choice of solvent for EDC can also affect immobilization efficiency. EDC is used frequently to carry out coupling of biomolecules in aqueous solution. However, because of the slow formation of O-acylurea intermediate and its

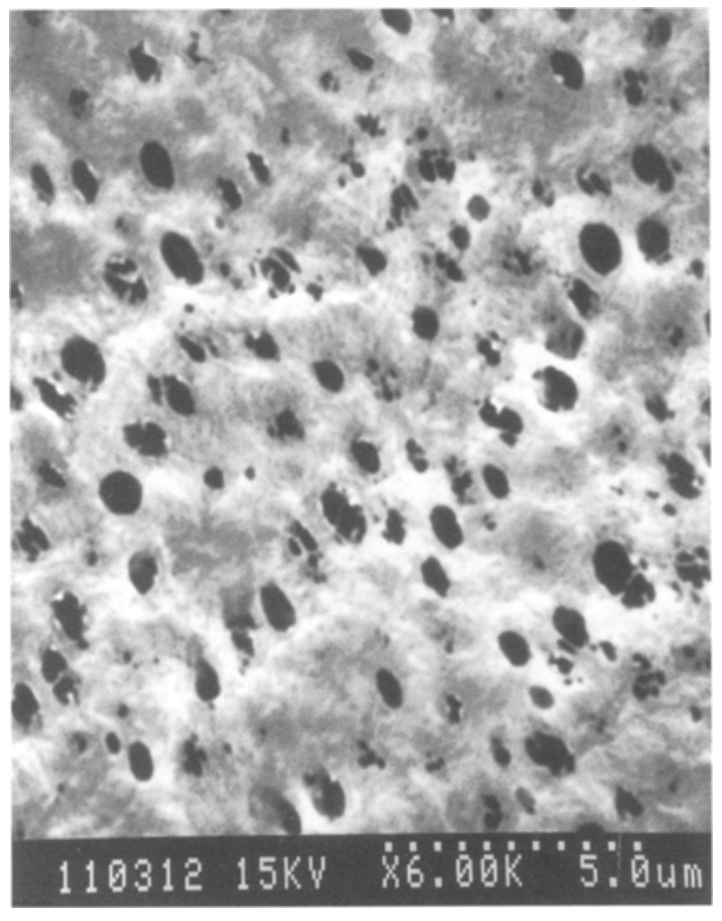

Fig. 2. Scanning electron micrograph of the gold coating on a microporous nylon membrane 
relatively quick hydrolysis, the efficiency of protein modification in an aqueous medium has been questioned. Although coupling efficiency of small molecules in homogeneous aqueous solution phase has been improved via use of sulfo-Nhydroxysuccinimide to stabilize the O-acylurea intermediate [23], such an approach may not be as effective when trying to immobilize much larger protein molecules on solid surfaces, due to the slow kinetics of the heterogeneous reaction. Therefore, in this work, acetonitrile was chosen as the solvent in which EDC activates the thioctic acid carboxyl group of the self-assembled monolayer. Acetonitrile is inert enough to prevent the solvolysis of the O-acylurea intermediate and, at the same time, polar enough to enable EDC to completely dissolve. As a result, the efficiency in activating the thioctic acid is high and hence so is the final protein immobilization.

\section{Colorimetric Determination of Alkaline Phosphatase Immobilization Efficiency}

Table 2 summarizes the results obtained for the immobilization of an enzyme, alkaline phosphatase, on the same series of gold coated membranes (untreated, inactivated monolayer, activated monolayer). The washing solutions were assayed instead of the immobilized disks because with high loading of enzyme at the gold surface, the enzymatic reaction is controlled by substrate diffusion and not enzyme activity. The immobilization results are different than those obtained for antibody immobilization, but the general trend is similar. Activation of the SAM enhances the immobilization. However, a significant amount of enzyme retention also occurs in the other two cases (bare gold, gold with an unactivated monolayer) compared to the relatively low antibody retention under the same circumstances. The stronger interaction between alkaline phosphatase and nonchemically modified bare gold surface suggests that exposed cysteine residues in alkaline phosphatase might be more accessible to interact with the gold surface than cysteines in the IgG molecules discussed above. Compared to antibodies, alkaline phosphatase also exhibits a stronger non-specific adsorption to the nylon matrix (in the case of non-EDC activated SAM/gold membrane).

Table 2. Results for immobilization of alkaline phosphatase on disc-shaped gold coated microporous nylon membrane with diameter of $6 \mathrm{~mm}$

\begin{tabular}{llll}
\hline Type of membrane $^{\mathrm{a}}$ & Bare gold & SAM only & SAM + EDC \\
\hline Immobilized ALP (U) $^{\mathrm{b}}$ & $11.87 \pm 1.2$ & $5.27 \pm 1.5$ & $14.06 \pm 0.8$ \\
\% of immobilization $^{\mathrm{c}}$ & 59.4 & 26.4 & 70.3 \\
\hline
\end{tabular}

a Bare gold, SAM only, and SAM + EDC bear the same meaning as the corresponding terms in Table 1.

b Alkaline phosphatase activity (mean \pm SD) as determined colorimetrically by subtracting the amount of enzyme in washing solution from the total enzyme applied to each gold coated membrane disc.

c Percentage of the amount of alkaline phosphatase retained by membrane over total amount applied to each membrane. Each value is the average of three measurements. 
Test of the Physical Strength of the Linkage Between Gold and Immobilized Protein

The data in Table 3 illustrates that when alkaline phosphatase immobilized gold coated microporous membranes are immersed in undiluted sheep serum, a similar amount of enzyme activity was found on membranes whether assayed immediately after the completion of immobilization (Group A), or after 48 hours of incubation in the sheep serum (subgroup B2). Lower enzyme activity was found for subgroup B1 membranes (those assayed twice, see experimental), probably due to damage caused by the harsh $\mathrm{pH}$ and ionic strength conditions incurred during the first assay. Obviously, the covalent attachment of alkaline phosphatase to gold is strong enough to resist displacement by proteins from serum. The choice of thioctic acid as a tether molecule contributes to the strength and stability of the immobilized protein layer. Indeed, two sulfur atoms of the thioctic acid are involved in forming two sulfur-gold thiolate bonds, providing a much stronger interaction between gold and thioalkyl molecule than with other thio-molecuels that possess only a single sulfur atom to form one sulfur-gold bond.

\section{EIA for hCG Using Anti-hCG Immobilized Gold Coated Microporous} Nylon Membrane As Solid Phase

Figure 3 shows the results obtained when using anti-hCG/gold coated nylon membranes as the solid phase to carry out a conventional sandwich enzyme immunoassay for detection of hCG. In this case, alkaline phosphatase was used as the labeling enzyme and the absorbance of the product ( $p$-nitrophenol) generated from substrate ( $p$-nitrophenyl phosphate) was used as the analytical signal. For high hCG concentrations (up to $150 \mathrm{U} /$ ), the immunobound enzyme activity is very high (but not enough to make mass transfer of substrate to the surface the limiting step for enzymatic reaction), and the solution of product must be diluted to obtain reliable absorbance values. At concentrations of hCG larger than 150 $\mathrm{U} / 1$, mass transfer of substrate to the surface enzyme becomes the limiting process that causes nonlinearity of the calibration curve. The detection limit for hCG, determined at a signal-to-noise ratio of 3 , is $0.4 \mathrm{U} / 1(0.08 \mathrm{ng} / \mathrm{ml})$. This is significantly lower than most previously published reports describing heterogeneous EIAs for hCG [24-26]. The assay also has a linear range of $0.5-150 \mathrm{U} / 1$. The low

Table 3. Stability test of immobilized alkaline phosphatase to gold coating on microporous nylon membrane

\begin{tabular}{lccc}
\hline $\begin{array}{l}\text { Type of membrane } \\
\text { Enzyme activity }\end{array}$ & Group A & Group B1 & Group B2 \\
\hline${ }^{\mathrm{a}}$ Group A: membranes were assayed immediately following the completion of \\
immobilization; Group B1: assayed membranes from Group A were rinsed \\
and immersed into sheep serum for 48h, then assayed; Group B2: following \\
the immobilization, membranes were immersed in sheep serum for $48 \mathrm{~h}$ and \\
then assayed. \\
retention of enzyme activity (mean $\pm \mathrm{SD}$ ) on each membrane.
\end{tabular}




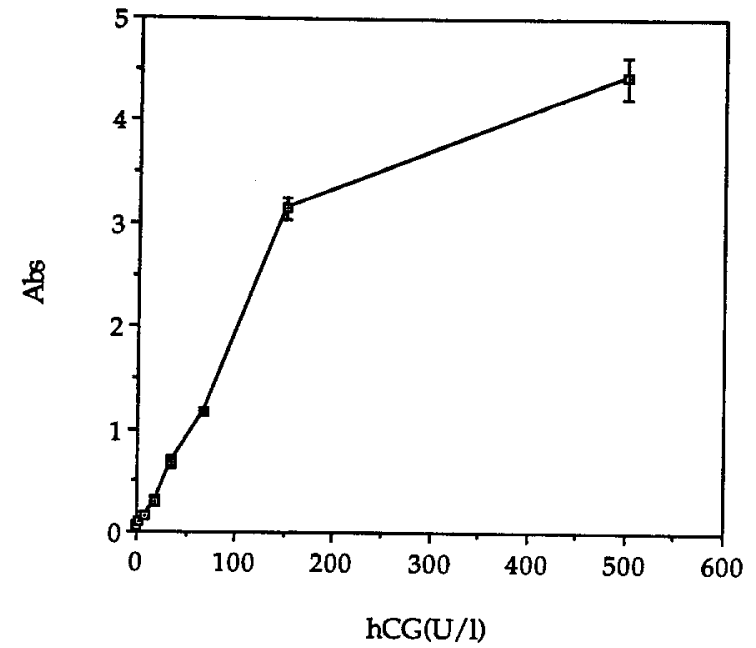

Fig. 3. Calibration curve for sandwich enzyme immunoassay of hCG using capture antibody immobilized on gold coated microporous nylon membranes. hCG concentrations: $0,0.5,2.5,7.5,17.5,35,67.5,150$, and 500 units/1. Each standard of hCG was assayed three times and the average plotted. The error bars indicate the range of values for each standard

detection limit and wide dynamic range demonstrates the feasibility of using antibody immobilized on gold coated nylon membrane for analysis of proteins.

As was pointed out earlier, one potential advantage of using the protein immobilization strategy described here is the excellent electrochemical characteristics of gold. Even after the immobilization of antibody on the gold surface, the gold coated membrane still functions satisfactorily as the working electrode for amperometric detection of electroactive species [22]. Indeed, based on this protein immobilization method, a non-separation, sandwich type electrochemical enzyme immunoassay has been developed for detection of proteins in undiluted whole blood [22] and viruses (potato virus A) in plant sap [unpublished data]. It is envisioned that this immobilization method could also be used in the development of other novel bioanalytical systems. For example, membranes possessing immobilized enzymes could be employed as efficient enzyme reactors/enzyme electrode detectors in flow-through systems (e.g., FIA) devised to detect given sustrates (e.g., glucose). Further, novel flow-through immunoassays such as those described by Wilson [27] and others [28-30] could also be implemented more conveniently using the immobilized antibody/gold coated microporous membrane described here. In such systems, the same gold coated membrane can serve simultaneously as an immunoreactor and transducer so that dilution of the product formed from the bound enzyme labeled antibody would be minimized when compared to previous systems where the detectors are often placed downstream from the immunosorbent phase.

\section{Conclusion}

It has been shown that a gold coated microporous nylon membrane can be modified with an activated SAM of thioctic acid. The ability of this membrane to immobilize various types of proteins was studied. The use of activated thioctic acid as a bridge to connect proteins to gold results in efficient protein immobilization with high stability. The immobilized antibody can be stored for more than 6 months in the refrigerator without noticeable loss of its immunological activity. 
The microporosity of the gold coated nylon membrane provides a very large surface area, which aids the immobilization efficiency. The usefulness of the proposed immobilization format has been demonstrated in its application to colorimetric ELISA for hCG as presented in this paper as well as for development of a novel non-separation ELISA for proteins [22] and viruses [unpublished data]. While reported here as a single use biomembrane/detector, the immobilized proteins can withstand repeated washings under mild conditions without loss of biological activity. In addition, we have found that proteins immobilized on gold by the SAM methodology reported here are in fact stable after being polarized at potentials ranging from $-0 .-+0.5 \mathrm{~V}$ vs $\mathrm{Ag} / \mathrm{AgCl}$. Thus, advantageous application of this protein immobilization method to other bioanalytical electrochemical detection systems seems likely.

Acknowledgement. We gratefully acknowledge Hybritech Inc. (La Jolla, CA) for their support and for providing some of immunoreagents used in this work. This work was supported in part by a grant from the National Science Foundation (CHE-9119728).

\section{References}

[1] O. Zaborsky, Immobilized Enzymes, CRC, Cleveland, 1973.

[2] G. G. Guilbault, Analytical Uses of Immobilized Enzymes, Dekker, New York, 1984.

[3] P. W. Carr, L. D. Bowers, Immobilized Enzymes in Analytical and Clinical Chemistry, Wiley New York, 1980.

[4] S. S. Wong, Chemistry of Protein Conjugation and Cross-Linking, CRC, Boca Raton, 1991.

[5] C. D. Stalikas, M. I. Karayannis, S. M. Tzouwara-Karayanni, Analyst 1993, 118, 723-726.

[6] N. Saito, H. Kawaguchi, Y. Ohtsuka, N. Shimizu, S. Inayama, Chem. Pharm. Bull. 1991, 39, 3085.

[7] T. Hayashi, C. Hirayama, M. Iwatsuki, J. Appl. Polymer Sci. 1992, 44, 143.

[8] H. Eckstein, H. J. Renner, H.Brun, Biomed. Biochim. Acta 1991, 50 , S114.

[9] W. Schramm, S. H. Paek, G. Voss, Immunomethods 1993, 3, 93.

[10] B. König, M. Grätzel, Anal. Chim. Acta 1993, 276, 329.

[11] J. M. Fernández-Romero, M. D. Luque de Castro, Anal. Chem. 1993, 65, 3048.

[12] K. Stein, G. Schwedt, Anal. Chim. Acta 1993, 272, 73.

[13] Y. Shan, I. D. McKelvie, B. T. Hart, Anal. Chem. 1993, 65, 3053.

[14] M. A. Dasilva, M. H. Gil, J. S. Redinha, A. M. O. Brett, J. L. C. Pereira, J. Polymer Sci. A 1991, $29,275$.

[15] J. J. Hickman, D. Ofer, P. E. Laibinis, G. M. Whitesides, M. S. Wrighton, Science 1991, 252, 688.

[16] I. Rubenstein, S. Steinberg, Y. Tor, A. Shanzer, J. Sagiv, Nature 1988, 332, 426.

[17] L. Sun, B. Johson, T. Wade, R. M. Crooks, J. Phys. Chem. 1990, 94, 8869.

[18] C. Miller, P. Cuendet, R. M. Grätzel, J. Phys. Chem. 1991, 95, 877.

[19] C. E. D. Chidsey, D. Loiacono, Langmuir 1990, 6, 682.

[20] T. Li, M. J. Weaver, J. Am. Chem. Soc. 1984, 106, 6107.

[21] Q. Cheng, A. Brajter-Toth, Anal. Chem. 1992, 64, 1998.

[22] C. Duan, M. E. Meyerhoff, Anal. Chem. 1994, 66, 1369.

[23] J. V. Staros, R. W. Wright, D. M. Swingle, Anal. Biochem. 1986, 156, 220.

[24] G. A. Robinson, H. A. O. Hill, R. D. Philo, J. M. Gear, S. J. Rattle, G. C. Forrest, Clin.Chem. $1985,31,1449$. 
[25] J. C. Thompson, J. A. Mazoh, A. Hochberg, S. Y. Tseng, J. L. Seago, Anal. Biochem. 1991, 194, 295.

[26] R. J. Norman, R. H. Buck, S. F. De Medeiros, Ann. Clin. Biochem. 1990, $27,183$.

[27] W. U. Alwis, G. S. Wilson, Anal. Chem. 1985, 57, 2754.

[28] Y. Xu, H. B. Halsall, W. R. Heineman, J. Pharm. Biomed. Anal. 1989, 7, 1301.

[29] Y. Xu, H. B. Halsall, W. R. Heineman, Clin. Chem. 1990, 36, 1941.

[30] E. P. Gil, H. T. Tang, H. B. Halsall, W. R. Heineman, A. S. Misiego, Clin. Chem. 1990, 36, 662.

Received June 20, 1994. Revision August 30, 1994. 